\title{
Historical Cohort Study on the Factors Affecting Blood Pressure in Work- ers of Polyacryl Iran Corporation Using Bayesian Multilevel Modeling with Skew T Distribution
}

\author{
Mohammad Gholami Fesharaki ${ }^{1}$, Anoshirvan Kazemnejad ${ }^{1 . *}$, Farid Zayeri ${ }^{2}$, Javad Sanati $^{3}$, \\ Hamed Akbari ${ }^{4}$ \\ ${ }^{1}$ Biostatistics Department, Faculty of Medical Sciences, Tarbiat Modares University, Tehran, IR Iran \\ 2 Proteomics Research Center, Faculty of Paramedical Sciences, Shahid Beheshti University of Medical Sciences, Tehran, IR Iran \\ ${ }^{3}$ Occupational Health Center, Polyacryle Company, Tehran, IR Iran \\ ${ }^{4}$ Health Research Center, Baqiyatallah University of Medical Sciences, Tehran, IR Iran \\ * Corresponding author: Anoshirvan Kazemnejad, Biostatistics Department, Faculty of Medical Sciences, Tarbiat Modares University, Tehran, IR Iran. Tel: \\ +98-2182883875, Fax:+98-2182884524, E-mail:Kazem_an@modares.ac.ir
}

\section{A B S T R A C T}

Background: Hypertension is considered as a major public health problem in most countries due to its association with ischemic heart disease which causes cerebrovascular disease and death.

Objectives: The purpose of the present study was to study factors affecting Blood Pressure(BP).

Patients and Methods: The data were extracted from annual observation of the workers who worked in Polyacryl Iran Corporation (PIC) between 1998 and 2010. In this research, we assessed the effect of Body Mass Index (BMI), age, sex, job status, marital status, job schedule type, and education level on Systolic Blood Pressure (SBP) and Diastolic Blood Pressure (DBP) using Bayesian multilevel modeling with skew distribution using WinBUGS software.

Results: Totally 3965 persons participated in this study, 75(1.9\%) female and 3890 (98.1\%) male. In this study age, sex, BMI, job status, marital status, and education level had statistical association with SBP. The result for DBP was similar to SBP except the education level which had no statistical association.

Conclusions: Treating obesity, increasing physical activity and quality of married life are proposed as practical solutions to reduce BP.

Keywords: Blood Pressure; Cohort Studies; Multilevel Analysis

Copyright @ 2013 , Iranian Red Crescent Medical Journal; Published by Kowsar Corp.

\section{Background}

Blood Pressure (BP) is the force of blood pushing against the walls of the arteries as the heart pumps blood (1). If this pressure rises and stays high over time, is called hypertension. Hypertension is a chronic disorder which imposes heavy treatment and care costs (2) and it is a serious condition which can lead to coronary heart disease

(3), heart failure (4), stroke (5), devastating effect of other cardiovascular risk factors (like dyslipidemia, smoking, diabetes and obesity) (6), and other health problems (1,2, 7). The overall prevalence of hypertension is $17.8 \%$ in Iran (8), and its prevalence in the age group 30-55 and more than 55 are $23 \%$ and $50 \%$, respectively (9). Previous stud-

Article type: Research Article; Received: 25 Feb 2013; Revised: 30 Mar 2013; Accepted: 16 Apr 2013; Epub: 05 May 2013; Ppub: 05 May 2013

Implication for health policy/practice/research/medical education:

Our study is first historical cohort study with large and homogeny sample size in Iran that used Bayesian multilevel modeling with skew $t$ distribution (a powerful statistical method for analyzing longitudinal data) which investigates factors affecting blood pressure.

Please cite this paper as:

Gholami Fesharaki M, Kazemnejad A, Zayeri F, Sanati J, Akbari H. Historical Cohort Study on the Factors Affecting Blood Pressure in Workers of Polyacryl Iran Corporation Using Bayesian Multilevel Modeling with Skew T Distribution. Iran Red Cres Med J.2013;15(5): 418-23: DOI: 10.5812 /ircmj.10930

Copyright (C) 2013, Iranian Red Crescent Medical Journal; Published by Kowsar Corp.

This is an Open Access article distributed under the terms of the Creative Commons Attribution License (http://creativecommons.org/licenses/by/3.0), which permits unrestricted use, distribution, and reproduction in any medium, provided the original work is properly cited. 
ies have shown the association of various factors like obesity (10-12), age (13), gender (12,14-16), marital status (17), quality of married life (18), smoking and being exposed to cigarette smoke $(19,20)$, loud noise at work place (21), workload (22), stress $(23,24)$, diet and physical activity (25), shift work (26), gaining weight $(11,12)$ with BP.

\section{Objectives}

Considering the importance of BP and since different studies have reported contradicting findings regarding factors affecting it, we decided to perform this historical cohort study to investigate the factors affecting BP using Bayesian multilevel modeling with skew t distribution.

\section{Patients and Methods}

This historical cohort study enrolled employed workers of Polyacryl Iran Corporation (PIC) in the Esfahan city from 1998 to 2010 with average repetition of 6.5 times and mean interval of 2 years using census sampling method. PIC produces polyester yarn and fiber and is the only producer of acrylic fiber in Iran country. In this study, inclusion criteria were official employment and attending annual health examinations between 1998 and 2010, and exclusion criteria were treated previously for hypertension, retirement, death or dismissal. During this period, 22018 employees received the health examination. Based on the mentioned criteria, 4525 observations were excluded from the study. This study was approved by the ethical committee of the medical school of Tarbiat Modares University, issued on 05.11.2011. Its registration number is 5271065 . In this study, BP of both arms was measured in the sitting position after 5 minutes rest using a calibrated mercury sphygmomanometer. Also, weight and height were measured by a physician using calibrated equipment. In this study the variable shift schedule was categorized as routine rotating shifts (2 morning shifts, 2 evening shifts, 2 night shifts and 2 days off) and weekly rotating shifts (3 morning shifts, 3 evening shifts, and one day off every two weeks, Fridays always off). Regular day workers worked from morning to evening on weekdays, and had Thursdays and Fridays off. The morning, evening, and night shifts began at 7 AM, 3 PM, and 11 PM, respectively. Day workers worked from 7 AM to 3 PM on weekdays, Thursdays and Fridays off.

\subsection{Data Analysis}

In this study we used Bayesian multilevel modeling with skew t distribution. Multilevel modeling is a useful method for analyzing correlated and longitudinal data (27). Routine assumption in multilevel modeling considers normal distribution for random error terms. Unfortunately, this assumption may be unrealistic in some situations, since the normal distribution is not able to reflect all features of error terms appropriately and there- fore inferences about the model parameters may be misleading. To overcome this problem we considered skew t-distribution (28) instead of normal distribution for random error terms and then used Bayesian approach with vague prior distributions (assuming an exponential distribution with lambda 0.1 for degree of freedom, a normal distribution with mean 0 and variance 100 for the beta parameters, and postulating a gamma distribution with parameters alpha $=0.001$ and beta $=0.001$ for the variance parameters). Then we used WinBUGS software for Bayesian analysis. Results were based on every 100 draw from a Markov Chain Monte Carlo (MCMC) chain of length 11,000 with a burn-in of 1000 . This proved more than enough for convergence, and much shorter runs led to virtually identical results. In this paper we also checked normal distribution for random error terms with Kolmogorov-Smirnov test.

Table 1. The Demographicaland Baseline Characteristics Baseline of the Workers at Their First Health Examination

\begin{tabular}{|c|c|}
\hline \multicolumn{2}{|c|}{ Continuous Variables } \\
\hline Variables & $\operatorname{Median}($ Mean \pm SD $)$ \\
\hline Age, $y$ & $24.64(25.61 \pm 4.16)$ \\
\hline Work experience, y & $15.39(12.55 \pm 7.99)$ \\
\hline $\mathrm{BMI}^{\mathrm{a}}, \mathbf{k g} / \mathrm{m}^{2}$ & $25.58(25.65 \pm 3.43)$ \\
\hline $\mathrm{DBP}^{\mathrm{a}}, \mathbf{m m} \mathrm{Hg}$ & $77.50(77.62 \pm 7.68)$ \\
\hline $\mathrm{SBP}^{\mathrm{a}}, \mathrm{mm} \mathrm{Hg}$ & $120(120.92 \pm 11.23)$ \\
\hline \multicolumn{2}{|c|}{ Categorical Variables } \\
\hline Variables & No. $(\%),(n=3965)$ \\
\hline \multicolumn{2}{|l|}{ Sex } \\
\hline Female & $75(1.9)$ \\
\hline Male & $3890(98.1)$ \\
\hline \multicolumn{2}{|l|}{ Marriage } \\
\hline Married & $829(20.9)$ \\
\hline Single & $3136(79.1)$ \\
\hline \multicolumn{2}{|l|}{ Education } \\
\hline Diploma or lower diploma & $1562(39.4)$ \\
\hline Associated degree & $1427(36)$ \\
\hline Bachelor or upper & $976(24.6)$ \\
\hline \multicolumn{2}{|l|}{ Shift Schedule } \\
\hline Weekly rotating & $294(7.4)$ \\
\hline Routine rotating & $1776(44.8)$ \\
\hline \multicolumn{2}{|l|}{ Type of Job } \\
\hline Day workers & $1895(47.8)$ \\
\hline Blue-collar worker & $3656(92.2)$ \\
\hline White-collar worker & $309(7.8)$ \\
\hline
\end{tabular}

a Abbreviations: BMI, body mass index; DBP, diastolic blood pressure; SBP, systolic blood pressure 


\begin{tabular}{|c|c|c|c|c|c|c|}
\hline \multirow[t]{2}{*}{ Variables } & \multirow[t]{2}{*}{ MCMC ${ }^{\mathrm{a}}$ Beta } & \multirow[t]{2}{*}{ MCMC SD $^{\mathrm{a}}$} & \multirow[t]{2}{*}{ MCMC SE $^{\mathrm{a}}$} & \multicolumn{2}{|c|}{ MCMC $95 \%$ CI $^{\mathrm{a}}$} & \multirow[t]{2}{*}{ Pvalue } \\
\hline & & & & Lower & Upper & \\
\hline \multicolumn{7}{|l|}{ Age, y } \\
\hline$B M I^{\mathrm{a}}, \mathbf{k g} / \mathbf{m}^{2}$ & 0.42 & 0.018 & 0.002 & 0.42 & 0.45 & $<0.001$ \\
\hline Education & 0.67 & 0.036 & 0.003 & 0.59 & 0.75 & $<0.001$ \\
\hline Bachelor or upper & -1.65 & 0.509 & 0.032 & -2.66 & & \\
\hline Associated degree & -0.83 & 0.385 & 0.023 & -1.60 & -0.69 & 0.001 \\
\hline Diploma and lower diploma & \multicolumn{3}{|c|}{ Reference category } & & -0.08 & 0.016 \\
\hline \multicolumn{7}{|l|}{ Shift schedule } \\
\hline Weeklyrotating shift workers & 0.35 & 0.648 & 0.030 & -0.91 & 1.61 & 0.295 \\
\hline Routine rotating shiftworkers & 0.33 & 0.378 & 0.023 & -0.370 & 1.11 & 0.191 \\
\hline
\end{tabular}

\section{Type of job}

\begin{tabular}{|c|c|c|c|c|c|c|}
\hline Day workers & \multicolumn{6}{|c|}{ Reference category } \\
\hline Blue-collar worker & -1.17 & 0.67 & 0.061 & -2.6 & 0.11 & 0.040 \\
\hline White-collar worker & \multicolumn{6}{|c|}{ Reference category } \\
\hline \multicolumn{7}{|l|}{ Marriage } \\
\hline Single & 7.28 & 0.551 & 0.049 & 6.33 & 8.53 & $<0.001$ \\
\hline Married & \multicolumn{6}{|c|}{ Reference category } \\
\hline \multicolumn{7}{|l|}{ Sex } \\
\hline Male & 10.60 & 1.135 & 0.110 & 8.41 & 12.87 & $<0.001$ \\
\hline Female & \multicolumn{6}{|c|}{ Reference category } \\
\hline Within subject variance & 5.65 & 0.419 & 0.038 & 4.83 & 5.65 & $<0.001$ \\
\hline Between subjects variance & 67.05 & 2.367 & 0.071 & 67.03 & 71.79 & $<0.001$ \\
\hline Skewnessparameter & 1.14 & 0.075 & 0.006 & 1.01 & 1.13 & $<0.001$ \\
\hline T degree of freedom & 7.50 & 0.49 & 0.042 & 0.04 & 6.62 & $<0.001$ \\
\hline
\end{tabular}

a Abbreviations: BMI, body mass index; CI, confidence interval; MCMC, markov chain monte carlo; SD, standard deviation; SE, standard error

\section{Results}

During 1998 to 20103965 workers and employees underwent the annual evaluation by the health and safety executive office of PIC. The mean follow up time of the workers was 6.5 repetitions. The demographical characteristics of the participants at their first health examination are presented in Table 1. According to this table, most subjects were male, married, educated as diploma or lower diploma, and they were day workers and blue-collar workers. Tables 2 and 3 show the summary of MCMC beta, their standard deviation, standard errors and statistical significance using Bayesian mul- tilevel modeling with skew $t$ distribution for the association between predictor variables on SBP and DBP respectively. According to the results, age, BMI, sex, job status, marital status and education level had statistical relation with SBP. The result for DBP was similar to SBP, except the education level which had no statistical association. In addition, significant parameter of Bayesian multilevel modeling with skew $\mathrm{t}$ distribution (within and between subject variance, skewness parameter and T degree of freedom) shows that such model is a convenient model for our historical data. 


\begin{tabular}{|c|c|c|c|c|c|c|}
\hline \multirow[t]{2}{*}{ Variables } & \multirow[t]{2}{*}{ MCMC $^{\text {a Beta }}$} & \multirow[t]{2}{*}{ MCMC SD ${ }^{\mathrm{a}}$} & \multirow[t]{2}{*}{ MCMC SE $^{\mathrm{a}}$} & \multicolumn{2}{|c|}{ MCMC $95 \%$ CI $^{\mathrm{a}}$} & \multirow[t]{2}{*}{ Pvalue } \\
\hline & & & & Lower & Upper & \\
\hline Age, y, & 0.46 & 0.013 & 0.001 & 0.43 & 0.48 & $<0.001$ \\
\hline $\mathrm{BMI}^{\mathrm{a}}, \mathbf{k g} / \mathrm{m}^{2}$ & 0.51 & 0.03 & 0.003 & 0.46 & 0.56 & $<0.001$ \\
\hline \multicolumn{7}{|l|}{ Education } \\
\hline Bachelor or upper & -0.10 & 0.36 & 0.02 & -0.80 & 0.65 & 0.391 \\
\hline Associated degree & 0.18 & 0.29 & 0.016 & -0.37 & 0.79 & 0.267 \\
\hline Diploma and lower diploma & \multicolumn{6}{|c|}{ Reference category } \\
\hline \multicolumn{7}{|l|}{ Shift schedule } \\
\hline Weekly rotating shift workers & -0.47 & 0.44 & 0.021 & -0.47 & 0.40 & 0.143 \\
\hline Routine rotating shiftworkers & -0.42 & 0.27 & 0.013 & -0.94 & 0.12 & 0.060 \\
\hline \multicolumn{7}{|l|}{ Type of job } \\
\hline Day workers & \multicolumn{6}{|c|}{ Reference category } \\
\hline Blue-collar worker & -1.25 & 0.44 & 0.038 & -2.08 & -0.30 & 0.002 \\
\hline White-collar worker & \multicolumn{6}{|c|}{ Reference category } \\
\hline \multicolumn{7}{|l|}{ Marriage } \\
\hline Single & 6.53 & 0.35 & 0.030 & 5.85 & 7.21 & $<0.001$ \\
\hline Married & \multicolumn{6}{|c|}{ Reference category } \\
\hline \multicolumn{7}{|l|}{ Sex } \\
\hline Male & 9.23 & 1.01 & 0.098 & 7.08 & 11.66 & $<0.001$ \\
\hline Female & \multicolumn{6}{|c|}{ Reference category } \\
\hline Within subject variance & 4.47 & 0.33 & 0.031 & 4.46 & 5.21 & $<0.001$ \\
\hline Between subjects variance & 34.92 & 1.29 & 0.049 & 32.49 & 37.51 & $<0.001$ \\
\hline Skewnessparameter & -1.18 & 0.07 & 0.006 & -1.32 & -1.04 & $<0.001$ \\
\hline T degree of freedom & 5.86 & 0.390 & 0.034 & 5.83 & 6.70 & $<0.001$ \\
\hline
\end{tabular}

a Abbreviations: BMI, Body Mass Index; CI, Confidence Interval; MCMC, Markov Chain Monte Carlo; SD, Standard Deviation; SE, Standard Error

\section{Discussion}

Because of the importance of hypertension, this study was performed to investigate the factors affecting BP in a historical cohort of PIC. In this study, Age showed a positive association with SBP and DBP, Each one-year increase in age elevated SBP and DBP by 0.42 and $0.46 \mathrm{mmHg}$, respectively. Several cohort and cross sectional studies have confirmed the direct association between BP and aging in different societies (13). BMI also had a direct association with SBP and DBP, indicating that obesity increases SBP and DBP. The direction and significance of this association were congruent with the findings of previous

studies. The direct correlation between obesity and BP has been confirmed in several studies (10-12). In our study, each 1-unit increase in BMI elevated SBP and DBP by 0.67 and $0.51 \mathrm{mmHg}$, respectively. Education also had a significant association only with SBP. Our results showed that individuals with higher levels of education had lower levels of BP, which could be due to higher income and job satisfaction. The results also showed that men had higher BP than women. This difference was $10.60 \mathrm{mmHg}$ for SBP and $9.23 \mathrm{mmHg}$ for DBP. This finding was in line with previous reports $(12,14-16)$. In our study, single participants showed higher BP compared to married ones. HoltLunstad et al. reported that marriage itself did not affect blood pressure, and stated that the quality of married life and couple's satisfaction was effective in lowering BP in married individuals (18). Moreover, Lipowicz et al. found that men who were never married had higher levels of BP when compared to married men. They used psychological indices (more stress and less social support), nutritional status, and economic situations of living a single life to justify this finding (17). Our findings showed an association between the type of job and BP. Blue-collar workers had lower BP compared to white-collar workers. It is because of more physical activity among blue-collar workers compared to white-collar ones. Respecting the results, our results did not support the association between shift schedule and BP. Studies have reported different and sometimes inconsistent results regarding the association of working on shift work and BP, they have 
mostly confirmed higher BP in shift workers when compared to day workers $(1,29-31)$. On the other hand, some studies like our study (32-38) found no significant association between BP and shift. This lack of association can be attributed to the fact that healthier individuals are usually recruited as shift workers while weaker ones are hired as day workers. Moreover, most of the day workers have administrative job and are therefore less active, leading to weight gain (a risk factor of BP elevation). Gholami et al. (39) found a significant increase in body mass index (around $0.78 \mathrm{~kg} / \mathrm{m} 2$ ) among day workers compared to weekly rotating shift workers. However, since the effect of shift work on individuals generally depends on the occupation, personal characteristics, workplace environment, and specifications of the shift work $(40,41)$, this association could be due to other reasons such as the variability of the work time and more income of the shift workers as compared to day workers. In the end, some of the advantages of this study are its longitudinal design, more than 6 years of follow up in average, using a complicated and powerful statistical modeling approach (Bayesian multilevel modeling with skew $t$ distribution), adequate sample size and homogeneity of the study population. However, lacks of access to family history of hypertension in close relatives, inability to evaluate the amount of rest and sleep, income, stress, job satisfaction, and smoking habit as confounding factors are considered some week points of our study. The results of this study demonstrated higher levels of BP in obese workers. We suggest running the SHIMSCO (42) plan to decrease obesity in PIC. Furthermore, considering the effect of marriage, quality of married life and couple's satisfaction with marriage on lowering BP, counseling sessions are recommended for married couples to enhance the quality of married life. Such counseling sessions can be also held before marriage to help individuals make correct decisions regarding their future life. Moreover, supporting single individuals financially is effective in lowering BP.

\section{Acknowledgements}

The authors sincerely express their appreciation to all the personnel of PIC, especially the staff of Industrial Medicine Department of the company, for their cooperation throughout the study.

\section{Authors' Contribution}

All authors contributed equally.

\section{Financial Disclosure}

There is no financial disclosure.

\section{Funding Support}

There is no funding or supports.

\section{References}

1. Wilson P, Kannel W. Hypertension,other risk factors and the risk of cardiovascular disease. In: laragh $\mathrm{JH}$, Brenner BM, editors. Hypertension :pathophysiology, diagnosis and management. 2nd ed. New York: Raven Press; 1995.

2. Lennernas M, Akerstedt T, Hambraeus L. Nocturnal eating and serum cholesterol of three-shift workers. Scand J Work Environ Health. 1994;20(6):401-6.

3. Lawes CM, Bennett DA, Lewington S, Rodgers A. Blood pressure and coronary heart disease: a review of the evidence. Semin Vasc Med. 2002;2(4):355-68.

4. Raphael CE, Whinnett ZI, Davies JE, Fontana M, Ferenczi EA, Manisty $\mathrm{CH}$, et al. Quantifying the paradoxical effect of higher systolic blood pressure on mortality in chronic heart failure. Heart 2009;95(1):56-62.

5. Endres M, Heuschmann PU, Laufs U, Hakim AM. Primary prevention of stroke: blood pressure, lipids, and heart failure. Eur Heart J. 2011;32(5):545-52.

6. Kario K, Schwartz JE, Davidson KW, Pickering TG. Gender differences in associations of diurnal blood pressure variation, awake physical activity, and sleep quality with negative affect: the work site blood pressure study. Hypertension. 2001;38(5):997-1002.

7. Nabe-Nielsen K, Garde AH, Tuchsen F, Hogh A, Diderichsen F. Cardiovascular risk factors and primary selection into shift work Scand J Work Environ Health. 2008;34(3):206-12.

8. McCubbin JA, Pilcher JJ, Moore DD. Blood pressure increases during a simulated night shift in persons at risk for hypertension Int J Behav Med. 2010;17(4):314-20.

9. Torsvall L, Akerstedt T, Gillberg M. Age, sleep and irregular workhours: A field study with electroencephalographic recordings, catecholamine excretion and self-ratings. Scand J Work Environ Health. 1981;7(3):196-203.

10. Alward RR, Monk TH, American Nurses Association. The nurse's shift work handbook. American Nurses Publishing; 2011.

11. Boggild H, Jeppesen HJ. Intervention in shift scheduling and changes in biomarkers of heart disease in hospital wards. Scand J Work Environ Health. 2001;27(2):87-96.

12. Murata K, Yano E, Shinozaki T. Impact of shift work on cardiovascular functions in a 10-year follow-up study. Scand J Work Environ Health. 1999;25(3):272-7.

13. Fransson EI, Alfredsson LS, de Faire UH, Knutsson A, Westerholm PJ. Leisure time, occupational and household physical activity, and risk factors for cardiovascular disease in working men and women: the WOLF study. Scand J Public Health. 2003;31(5):324-33.

14. Brown DL, Feskanich D, Sanchez BN, Rexrode KM, Schernhammer ES, Lisabeth LD. Rotating night shift work and the risk of ischemic stroke. Am J Epidemiol. 2009;169(11):1370-7.

15. de Munter JS, Agyemang C, van Valkengoed IG, Bhopal R, Stronks K. Sex difference in blood pressure among South Asian diaspora in Europe and North America and the role of BMI: a meta-analy sis. J Hum Hypertens. 2011;25(7):407-17.

16. Pati A, Chandrawshi A, Reinberg A. Shift work: consequence and management. Curr Sci. 2002;81(1):32-47.

17. Lipowicz A, Lopuszanska M. Marital differences in blood pressure and the risk of hypertension among Polish men. Eur J Epidemiol. 2005;20(5):421-7.

18. Holt-Lunstad J, Birmingham W, Jones BQ. Is there something unique about marriage? The relative impact of marital status, relationship quality, and network social support on ambulatory blood pressure and mental health. Ann Behav Med. 2008;35(2):239-44

19. Kivimaki M, Virtanen M, Elovainio M, Vaananen A, KeltikangasJarvinen L, Vahtera J. Prevalent cardiovascular disease, risk factors and selection out of shift work. Scand J Work Environ Health. 2006;32(3):204-8.

20. Seki M, Inoue R, Ohkubo T, Kikuya M, Hara A, Metoki H, et al. Asso- 
ciation of environmental tobacco smoke exposure with elevated home blood pressure in Japanese women: the Ohasama study. J Hypertens. 2010;28(9):1814-20.

21. Schnall PL, Schwartz JE, Landsbergis PA, Warren K, Pickering TG. Relation between job strain, alcohol, and ambulatory blood pressure. Hypertension. 1992;19(5):488-94.

22. Chen JD, Lin YC, Hsiao ST. Obesity and high blood pressure of 12-hour night shift female clean-room workers. Chronobiol Int. 2010;27(2):334-44

23. Hermansson J, Gillander Gadin K, Karlsson B, Lindahl B, Stegmayr B, Knutsson A. Ischemic stroke and shift work. Scand J Work Environ Health. 2007;33(6):435-9.

24. Kawakami N, Haratani T, Araki S. Job strain and arterial blood pressure, serum cholesterol, and smoking as risk factors for coronary heart disease in Japan. Int Arch Occup Environ Health. 1998;71(6):429-32.

25. Zemel MB. Dietary pattern and hypertension: the DASH study. Dietary Approaches to Stop Hypertension. Nutr Rev. 1997;55(8):303-5.

26. Suwazono Y, Dochi M, Sakata K, Okubo Y, Oishi M, Tanaka K, et al. Shift work is a risk factor for increased blood pressure in Japanese men: a 14-year historical cohort study. Hypertension. 2008;52(3):581-6.

27. Hox JJ. Multilevel Analysis: Techniques and Applications (Quantita tive Methodology Series). 2nd ed. Great Britain: Routledge; 2010.

28. Gupta AK. Multivariate skew t-distributions. Statistics. 2003;37:359-63.

29. Ghiasvand M, Heshmat R, Golpira R, Haghpanah V, Soleimani A, Shoushtarizadeh P, et al. Shift working and risk of lipid disorders: a cross-sectional study. Lipids Health Dis. 2006;5:9.

30. Morikawa Y, Nakagawa H, Miura K, Ishizaki M, Tabata M, Nishijo $\mathrm{M}$, et al. Relationship between shift work and onset of hypertension in a cohort of manual workers. Scand J Work Environ Health. 1999;25(2):100-4.

31. Oishi M, Suwazono Y, Sakata K, Okubo Y, Harada H, Kobayashi E, et al. A longitudinal study on the relationship between shift work and the progression of hypertension in male Japanese workers. J Hypertens. 2005;23(12):2173-8.
32. Hublin C, Partinen M, Koskenvuo K, Silventoinen K, Koskenvuo M, Kaprio J. Shift-work and cardiovascular disease: a populationbased 22-year follow-up study. Eur J Epidemiol. 2010;25(5):315-23.

33. Merijantia LT, Samara D, Tandean R. The role of night shift work on blood pressure among healthy female nurses. UNIVERS MED. 2008;27(2):65-71.

34. Murata K, Yano E, Hashimoto H, Karita K, Dakeishi M. Effects of shift work on QTc interval and blood pressure in relation to heart rate variability. Int Arch Occup Environ Health. 2005;78 (4):287-92.

35. Puttonen S, Kivimaki M, Elovainio M, Pulkki-Raback L, Hintsanen $\mathrm{M}$, Vahtera J, et al. Shift work in young adults and carotid artery intima-media thickness: The Cardiovascular Risk in Young Finns study. Atherosclerosis. 2009;205(2):608-13.

36. Sfreddo C, Fuchs SC, Merlo AR, Fuchs FD. Shift work is not associated with high blood pressure or prevalence of hypertension. PLoS One. 2010;5(12)

37. Virkkunen H, Harma M, Kauppinen T, Tenkanen L. Shift work, occupational noise and physical workload with ensuing development of blood pressure and their joint effect on the risk of coronary heart disease. Scand JWork Environ Health. 2007;33(6):425-34.

38. Yadegarfar G, McNamee R. The 'healthy shift worker effect' in the relationship between shift work and longitudinal change in blood pressure. Annal epidem. 2003;13(8):585-586.

39. Gholami Fesharaki M, Kazemnejad A, Zayeri F. Relationship between shift work and obesity; a retrospective cohort study. Iran J Milit Med. 2012;14(2):93-7.

40. Gholami Fesharaki M, Rozati M, Tanhai AR. The longitudinal study of the relationship between work shift and blood pressure in workers of Mobarakeh Steel Company of Isfahan in 20072009. Arak Med Uni J(AMUJ). 2010;13(4):68-74.

41. Smith L, Folkard S, Tuker P. Work shift duration: a review comparing eight hour and 12 hour shift systems. J Occup environ Med. 1998;55:217-29.

42. Khosravi AR, Rowzati M, Gharipour M, Fesharaki MG, Shirani S, Shahrokhi S, et al. Hypertension control in industrial employees: findings from SHIMSCO study. ARYA Atheroscler. 2012;7(4):191-6. 